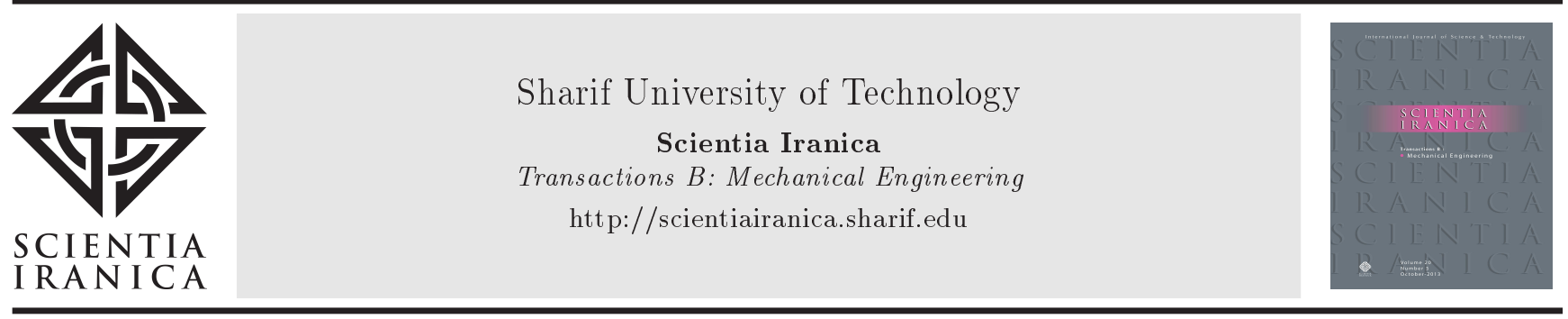

\title{
Influence of bladed and glazed entrance on the performance of solar air heater
}

\author{
A.E. Kabeel ${ }^{a, *}$, M.H. Hamed ${ }^{\text {b,c }}$, Z.M. Omara ${ }^{\mathrm{b}}$, and A.W. Kandeal ${ }^{\mathrm{b}}$ \\ a. Faculty of Engineering, Tanta University, Tanta, Egypt. \\ b. Faculty of Engineering, Kafrelsheikh University, Kafrelsheikh, Egypt. \\ c. Higher Institute of Engineering and Technology, HIET, Kafrelsheikh, Egypt.
}

Received 1 November 2017; received in revised form 2 January 2018; accepted 12 February 2018

\section{KEYWORDS}

Single-pass solar air heater;

Entrance region;

Glass cover;

Guide blades;

Daily efficiency.

\begin{abstract}
The performance of a flat-plate single-pass Solar Air Heater (SAH), modified in the entrance region, was experimentally investigated. This entrance region was covered with glass instead of steel. Using glass cover in the entrance region increases the exposure of the heating area to solar radiation; however, using steel cover prevents solar radiation from reaching this area. In addition, guide blades were placed in the entrance region to ensure well air distribution on the absorber surface and, hence, enhancement of the thermal performance of SAH. The modified SAH was compared with that at the conventional entrance. The experiments were performed at four airflow rates, which ranged from 0.013 to $0.04 \mathrm{~kg} / \mathrm{s}$. The modifications led to good improvement in both the air temperature difference and the efficiency. For the daily efficiency, the maximum values include $43.43,40.48$, and $32.92 \%$ for the glazed-bladed entrance SAH, glazed entrance SAH, and conventional SAH, respectively, at a rate of $0.04 \mathrm{~kg} / \mathrm{s}$. The glazed-bladed $\mathrm{SAH}$ showed good improvement in the daily thermal efficiency by 6.72 to $10.5 \%$ over the conventional heater and by 2.16 to $3.25 \%$ over the glazed SAH.
\end{abstract}

(C) 2019 Sharif University of Technology. All rights reserved.

\section{Introduction}

SAHs are used in many applications such as space heating, drying applications, and water desalination. They are more advantageous than liquid heaters, because the used fluid air is not as freezable or stagnant as liquids and has no environmental or health hazards [1]. Moreover, SAHs have a simple construction of thermally insulated duct covered with glass cover. The main component is the absorber plate with heating capacity to store the heat gained from the sun and heat from the

\footnotetext{
*. Corresponding author. Tel.: +20 1001543587; Fax: +20403453860

E-mail addresses: kabeel6@hotmail.com and kabeel6@f-eng.tanta.edu.eg (A.E.Kabeel)
}

flowing air. Since the heat transfer between the flowing air and the absorber plate is low, many investigators aimed to apply many modifications to the absorber plate to enhance the performance of SAHs.

Many researchers studied different parameters that affect the performance of the simplest configurations of SAHs (and flat plate $\mathrm{SAH}$ ) such as mass flow rate $(\dot{m})$, solar radiation $\left(I_{(t)}\right)$, number of glass covers, tilt angle, number of passes, and absorber configurations with various corresponding attachments. Sharma et al. [2] aimed to analytically optimize a set of different operating parameters that affect smooth flat plate SAH: glass cover number, plate emissivity, mean temperature, temperature rise, tilt angle, and solar radiation intensity at different Reynolds numbers. In addition, dimensionless models were presented to optimize the aspect ratio of flat plate $\mathrm{SAH}$ and the outlet temperature $\left(T_{\text {out }}\right)[3,4]$. In addition, different 
cross-sections and geometries of the SAH duct and absorbers were studied by some researchers such as the experimental investigation performed by Abdullah et al. [5] on three SAHs having different crosssectional shapes (circular, semi-circular, and half-circle plus isosceles triangle) with an absorber identical to a half-circle shape. The values of thermal efficiency $(\eta)$ reached 80,64 , and $48 \%$ for the circular, halfcircle plus isosceles triangle, and semi-circular shapes, respectively.

The improving methods aim essentially to improve the thermal and thermo-hydraulic performance, which depends essentially on enhancing the heat transfer characteristics. One of these methods is attaching fins to increase the heat transfer area. Different shapes of fins have been studied. First, longitudinal fins have been studied by many researchers either experimentally $[6-8]$ or theoretically $[9,10]$. The results of such studies confirmed that attaching fins to the absorber plate improved the performance of SAH due to a higher heat transfer area and lower irreversibility compared to flat-plate SAH. Decreasing fins spacing and increasing fins height enhance the thermal and thermohydraulic efficiencies by 114.1 and $112.65 \%$, respectively, as concluded in [9]. In addition, the recycling process with various reflux ratios was studied to obtain the ratio that achieves the best performance of finned SAHs [11-13]. Furthermore, other shapes of fins can also be used to enhance the performance of SAHs such as wavy fins [14,15] and v-corrugated fins $[16,17]$ with improvement in efficiency of both single- and double-pass SAHs.

Improving the heat transfer can be accomplished by the improving thermo-hydraulic performance by creating a turbulent flow using artificial roughness. Many works proved the significance of using artificial roughness at different geometries such as different shapes of ribs [18-21], obstacles [22,23], and arc wires and protrusions [24,25]. Furthermore, artificial roughness can be added to the sides of SAH, leading to greater enhancement according to $[26,27]$.

Using energy storage, absorbers coating, and packed bed enhances the performance of energy systems and their role in energy conservation. Energy storage is commonly considered in areas with variations in solar energy and areas with high temperature variation between day and night. The most common energy storage materials are Phase Change Materials (PCMs), whose ability was proved to enhance the performance of SAHs according to the studies made by many researchers such as Krishnananth and Kalidasa Murugavel [28], Alkilani et al. [29], and Moradi et al. [30]. Using PCMs affects the performance of finned [31] and corrugated plate $\mathrm{SAHs}$ [32]. In addition, the absorbing efficiency depends on the absorber plate coating which takes into account the absorptivity of the absorber plate as ensured by El-Sebaii and AlSnani [33] compared to the results reported in [34], in which nickel-tin (Ni-Sn) proved to have the best performance.

In addition, using different beds on the absorber improves the performance. According to Ramani et al. [35], double-pass SAH with porous material has $\eta$ about $20-25 \%$ and $30-35 \%$ higher than that of doublepass $\mathrm{SAH}$ without porous material and single-pass $\mathrm{SAH}$, respectively. Dissa et al. [36] designed and experimented on a SAH with a composite absorber of a non-porous corrugated iron sheet and porous mesh of aluminum. The value of midday $\eta$ reached $61 \%$. An unsteady state model ensured the results. In addition, using steel wire mesh as beds showed good improvement in the SAHs performance $[37,38]$. Moreover, the metal corrugated packing $\mathrm{SAH}$ was ensured to be more appropriate to use in cold-region rural buildings due to the advantages such as large heat transfer area, high heat transfer coefficient, and good economic performance, as studied by Zheng et al. [39].

Many studies in the field of SAHs are concerned with the entrance region; however, its extreme importance lies in the heat gain during the temperature rise when calculating efficiency. Therefore, the aim of the current study is to study the effect of the modifications made in the entrance region on the performance of a flat-plate SAH of a single-pass type.

The entrance region studied by a number of researches' test rigs had a conical shape, or a shape different from opaque materials $[17,31,32,40]$. The present study aims to replace the opaque material or steel used at entrance by glass cover to increase the exposure of the heating area to solar radiation. In addition, replacing the opaque or steel cover with glass prevents the solar radiation from reaching the area of the entrance region as in the case of steel cover. Restricting solar radiation leads to lower temperatures in the entrance region as compared to the absorber; hence, heat is dissipated by decreasing the absorber surface temperature and the outlet air temperature.

In addition, the heating efficiency depends on the distribution of the air through the whole area of the duct and elimination of dead zones. Thus, air distribution has an effective role in improving the performance of SAHs. Therefore, to ensure uniformly air distribution and overcome the problem of pressure drop across the air distribution systems, simple fixed air directing blades are used in the present study. The blades are made of aluminum, leading to their additional role in fins at the entrance to enhance the heat transfer at the heater entrance.

According to the previous review, the effect of glazing the entrance region on the flat-plate $\mathrm{SAH}$ has not been recognized. In addition, the effect of attaching guide blades to the entrance region has not 


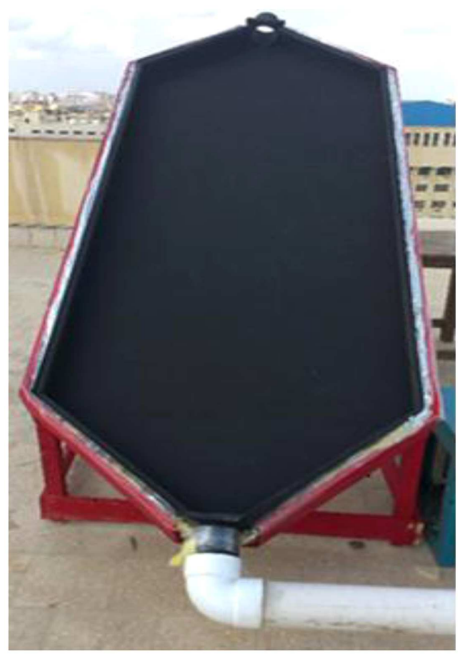

(a) Flat plate SAH with glass cover at entrance

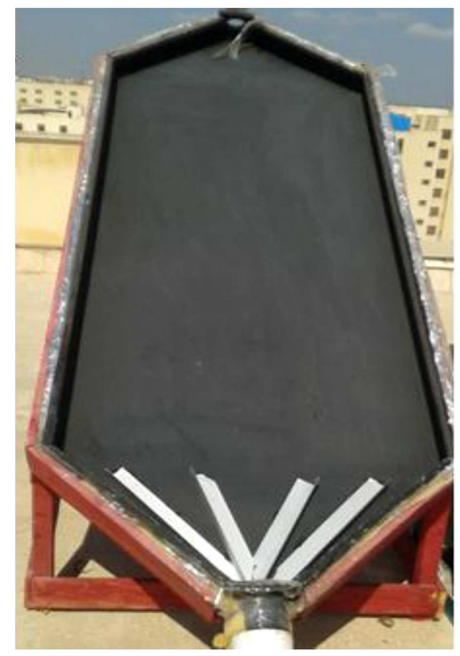

(b) Flat plate SAH with directing blade (unpainted)

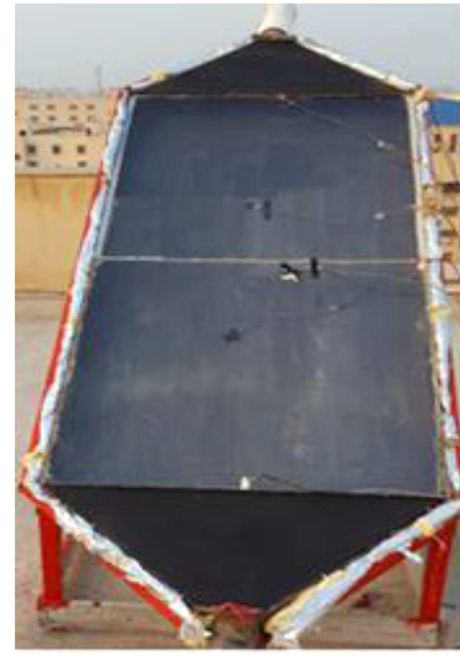

(c) Flat plate SAH with steel cover at entrance

Figure 1. Photos of the tested heaters.

been studied in detail. Therefore, the present work experimentally studies the performance of a flat-plat $\mathrm{SAH}$ with new modifications in the entrance region (glazed-bladed entrance SAH) and compares it with the conventional SAH. In the present paper, the following test cases are carried out:

1. The effect of glazing the entrance of a flat-plate $\mathrm{SAH}$ (glazed entrance SAH) compared to another one with steel entrance (conventional SAH);

2. The effect of attaching guide blades to the glazed entrance $\mathrm{SAH}$ (glazed-bladed entrance $\mathrm{SAH}$ ) as compared to the conventional one.

\section{Experimental setup and procedure}

Two SAHs are designed and fabricated from commercial available materials. One of them is the modified SAH, and the other is the conventional SAH. In addition, the SAHs are equipped with measuring instruments to measure the parameters affecting the thermal efficiency (solar radiation, air mass flow rate, and both inlet and outlet temperatures).

\subsection{Experimental setup description}

The test rig consists of a conventional flat-plate $\mathrm{SAH}$ and another modified plate SAH. Each heater is made of galvanized steel with thickness of $1.5 \mathrm{~mm}$. The dimensions of the heater duct include the length of $200 \mathrm{~cm}$ and width of $100 \mathrm{~cm}$ with sidewall height of $10 \mathrm{~cm}$. The whole internal surface is painted black to increase their absorptivity. In addition, to prevent the heat loss into the surrounding, the heaters are well insulated with glass-wool insulation material. The heaters are tilted with approximately $30^{\circ}$ on the horizontal according to the latitude of Kafrelsheikh city, Egypt. Each SAH was covered with a sheet of commercial glass of $4 \mathrm{~mm}$ thick with silicon sealant to prevent any air leakage. Each heater is made of conical shape passage at entrance and exit of $40 \mathrm{~cm}$ length with passage variation from $10 \mathrm{~cm}$ to $100 \mathrm{~cm}$ with the same sidewall height of the duct. In modified SAHs, the entrance region is covered with glass cover as the first modification. In addition, four guide blades made of aluminum are fixed in the entrance region as the second modification, while, for the conventional $\mathrm{SAH}$, the entrance and exit regions are covered with steel without using guide blades in the entrance region. Figure 1 illustrates the tested SAHs. In addition, Figure 2 shows a schematic diagram of the test setup. In addition, Table 1 summarizes the specifications of the SAH.

The air is forced via a centrifugal air blower of a blade diameter of $30 \mathrm{~cm}$ connected to an $\mathrm{AC}$ electric motor powered by a photovoltaic (PV) system consisting of PV cell, battery, charger, and converter (DC to AC). The used PV cell is a silicon solar panel

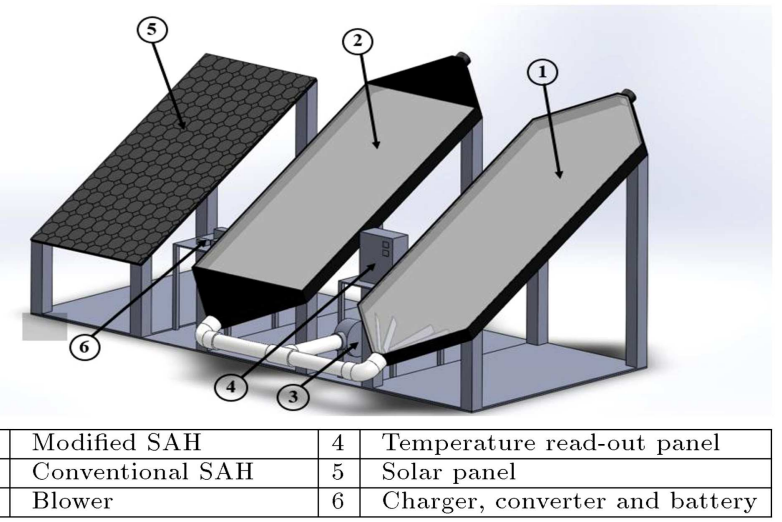

Figure 2. A schematic diagram of the test setup. 
Table 1. Specifications of the SAH.

\begin{tabular}{ll}
\hline \multicolumn{1}{c}{ Component } & \multicolumn{1}{c}{ Type and specifications } \\
\hline SAH duct & Galvanized steel of $200 \times 100 \times 10 \mathrm{~cm}$ \\
Entrance and exit & Divergent (entrance) and convergent (exit) ducts $100 \mathrm{~cm}$ for one end till $10 \mathrm{~cm}$ \\
& at the other end with $40 \mathrm{~cm}$ length \\
Blades & 4 aluminum blades oriented at nearly $24^{\circ}$ in-between angle \\
Coating & Industrial matt black (absorptivity of 0.95$)$ \\
Back and side insulation & Glass-wool $(5 \mathrm{~cm}$ thickness) \\
Glazing & Single glass cover $(0.4 \mathrm{~cm}$ thickness; absorptivity of $0.05 ;$ emissivity of 0.85$)$ \\
Tilt angle & $30^{\circ}$ with the horizontal \\
Outer frame & Wooden Frame \\
Sealant & Thermal Silicon \\
\hline
\end{tabular}

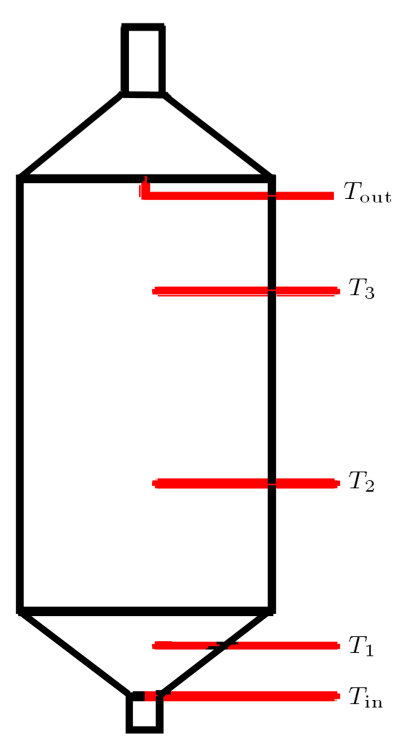

Figure 3. Positions of thermocouples.

$600 \mathrm{~W}$ with the area of $(1 * 1.6) \mathrm{m}^{2}$. A regulator is connected to the blower to obtain variable speeds of rotation and, hence, variable airflow rates according to the output voltage of the regulator. The airflow duct system consists of the main pipe, branching into two air pipes. Each pipe is of 4 inches made of PVC. Thermocouples of K-type are used for measuring various temperatures for either the airflow or the absorber surface. The airflow temperatures are measured at entrance $\left(T_{\text {in }}\right)$ and outlet $\left(T_{\text {out }}\right)$. In addition, the ambient temperature is measured. In addition, thermocouples are fixed at different points on the surface of the absorbers to measure the variation of temperature. Finally, to measure temperatures of the glass covers, thermocouples are fixed on their upper side. Figure 3 shows various positions of thermocouples along the surface of each SAH. $T_{1}, T_{2}$, and $T_{3}$ are the temperatures of the surface of the absorber along its centerline.

\subsection{Experimental procedure}

Two SAHs are tested experimentally in outdoor environment. The SAHs are installed to the south during the study. The measured quantities (solar radiation, air temperatures at different points, absorber surface temperature, ambient temperature, and glass cover temperatures) are measured from 9 am to $5 \mathrm{pm}$ at an hourly interval for various airflow rates. The temperatures measurements are recorded using calibrated K-type thermocouples. The readout of the thermocouples is monitored by temperature readers (TC4M-24R, Autonics). The readers are connected to two manual selectors. The global incident solar radiation on the surface is measured by means of data logging solar meter (TES-1333) with accuracy of $\pm 1 \mathrm{~W} / \mathrm{m}^{2}$ and at a range of $0-5000 \mathrm{~W} / \mathrm{m}^{2}$; the speed of air is measured using a van type anemometer accuracy of $\pm 0.1 \mathrm{~m} / \mathrm{s}$ at a range of $0-30 \mathrm{~m} / \mathrm{s}$. The experimental investigations of each modified $\mathrm{SAH}$ and the conventional one are carried out at the same time.

\subsection{The thermal efficiency of heaters}

The thermal efficiency of the SAH can be defined as reported in $[6,41]$ :

$$
\begin{aligned}
\eta & =\frac{\text { Useful energy gained }}{\text { Total solar incident on the SAH absorber }} \\
& =\frac{Q_{u}}{I_{(t)} \times A},
\end{aligned}
$$

where the gained useful energy can be defined by:

$$
Q_{u}=\dot{m} C_{p}\left(T_{\text {out }}-T_{\text {in }}\right) .
$$

\subsection{Experimental error analysis}

During designing and planning of experiments, uncertainty analysis is an effective, powerful tool. To estimate the uncertainty of the measured parameters and resulted data, the method reported in [42] is used. A measurement set is conducted to measure variables 
Table 2. Sample of experimental data.

\begin{tabular}{ccccc}
\hline Time and day & $\begin{array}{c}\boldsymbol{T}_{\text {in }} \\
\left({ }^{\circ} \mathbf{C}\right)\end{array}$ & $\begin{array}{c}\boldsymbol{T}_{\text {out }} \\
\left({ }^{\circ} \mathbf{C}\right)\end{array}$ & $\begin{array}{c}\boldsymbol{V}_{\text {air }} \\
(\mathbf{m} / \mathbf{s})\end{array}$ & $\begin{array}{c}\boldsymbol{I}_{(\boldsymbol{t})} \\
\left(\mathbf{W} / \mathbf{m}^{2}\right)\end{array}$ \\
\hline $12: 00$ & 23 & 51 & 4.5 & 1128 \\
$13 / 2 / 2017$ & \pm 1 & \pm 1 & \pm 0.1 & \pm 1 \\
\hline
\end{tabular}

of " $n$ " number. Let the result $R$ be a function of independent variables. Thus:

$$
R=R\left(X_{1}, X_{2}, X_{3} \cdots, X_{n}\right) .
$$

Let the uncertainty in the result be $W_{R}$ and the uncertainties in the independent variables be $W_{1}, W_{2}, W_{3}, \cdots, W_{n}$. Regarding the uncertainties in the independent variables, uncertainty in the result can be calculated by the following:

$$
\begin{aligned}
W_{R}= & {\left[\left(\frac{\partial R}{\partial X_{1}} W_{1}\right)^{2}+\left(\frac{\partial R}{\partial X_{2}} W_{2}\right)^{2}+\cdots\right.} \\
& \left.+\left(\frac{\partial R}{\partial X_{n}} W_{n}\right)^{2}\right]^{\frac{1}{2}} .
\end{aligned}
$$

By determining the relation between the measured quantities and the uncertainties of each quantity, uncertainty $W_{R}$ is calculated through Eq. (4).

Table 2 presents an example of the measured experimental data of the glazed-bladed SAH. Uncertainty of the measured parameters is given in Table 3 . The minimum error equals the ratio between its least count and minimum value of the output measured, as defined by [43]. Based on these measured data, $\eta$ can be calculated.

From the equation of $\eta$ :

$$
\eta_{t h}=\frac{\dot{Q}_{u}}{A_{h} I_{R}}=\frac{\dot{m} c_{p} \Delta T}{A_{h} I_{R}} .
$$

Since $A_{h}$ is constant and assuming that $C_{p}$ is constant for the range of measured temperatures:

$$
\eta_{t h}=f\left(\dot{m}, \Delta T, I_{R}\right)
$$

Following Eq. (6), total uncertainty for $\eta$ can be derived as follows:

$$
\begin{aligned}
W_{\eta_{t h}}= & {\left[\left(\frac{\partial \eta_{t h}}{\partial m} W_{m}\right)^{2}+\left(\frac{\partial \eta_{t h}}{\partial \Delta T} W_{\Delta T}\right)^{2}\right.} \\
& \left.+\left(\frac{\partial \eta_{t h}}{\partial I_{R}} W_{I_{R}}\right)^{2}\right]^{\frac{1}{2}} .
\end{aligned}
$$

Detailed calculations of various parameters are presented as follows:

i) The uncertainty of $\Delta T$ is:

$$
\begin{aligned}
W_{\Delta T} & =\left[\left(\frac{\partial \Delta T}{\partial T_{\text {in }}} W_{T_{\text {in }}}\right)^{2}+\left(\frac{\partial \Delta T}{\partial T_{\text {out }}} W_{T_{\text {out }}}\right)^{2}\right]^{\frac{1}{2}}, \\
W_{\Delta T} & =\left[( \pm 1 \times-1)^{2}+( \pm 1 \times 1)^{2}\right]^{0.5} \\
& = \pm 1.414^{\circ} \mathrm{C} .
\end{aligned}
$$

Then, the relative error is:

$$
E_{\Delta T}=\frac{1.414}{28}=5 \% \text {. }
$$

ii) For $\dot{m}$, the uncertainty can be calculated as follows:

$$
\dot{m}=\rho \cdot V_{\mathrm{air}} \cdot A_{p} .
$$

Let, $\rho=1.2 \mathrm{~kg} / \mathrm{m}^{3}$ and $A_{p}=0.00784 \mathrm{~m}^{2}$ :

$$
\begin{aligned}
& \dot{m}=0.009408 V_{\text {air }} \\
& \dot{m}=0.009408 * 4.5=0.04 \mathrm{~kg} / \mathrm{sec} .
\end{aligned}
$$

Then, the uncertainty is:

$$
\begin{aligned}
W_{m} & =\left[\left(\frac{\partial m}{\partial v} W v\right)^{2}\right]^{\frac{1}{2}} \\
W_{m} & =\left[( \pm 0.1 \times 0.009408)^{2}\right]^{0.5} \\
& = \pm 0.0009408 \mathrm{~kg} / \mathrm{s} .
\end{aligned}
$$

Then, the relative error is:

$$
E_{m}=\frac{0.0009408}{0.04}=2.352 \% \text {. }
$$

Table 3. Measurements uncertainties and relative errors.

\begin{tabular}{llc}
\hline \multicolumn{1}{c}{ Parameter } & Uncertainty & Relative error \\
\hline Air temperature difference $\left({ }^{\circ} \mathrm{C}\right)$ & \pm 1.414 & $5 \%$ \\
Air mass flow rate $(\mathrm{kg} / \mathrm{s})$ & \pm 0.0009408 & $2.352 \%$ \\
Solar radiation $\left(\mathrm{W} / \mathrm{m}^{2}\right)$ & \pm 1 & $0.0886 \%$ \\
Efficiency $(\%)$ & \pm 2.5 & $6.13 \%$ \\
\hline
\end{tabular}


iii) The uncertainty of the solar radiation is:

$$
W_{I_{R}}= \pm 1 \mathrm{~W} / \mathrm{m}^{2} \text {. }
$$

Then, the relative error is:

$$
E_{I(t)}=\frac{1}{1128}=0.0886 \% \text {. }
$$

Then, the uncertainty of $\eta$ can be calculated as follows:

$$
\begin{aligned}
W_{\eta}= & {\left[\left( \pm 0.0009408 \times \frac{1005 * 28}{2.2 * 1128}\right)^{2}\right.} \\
& +\left( \pm 1.414 \times \frac{0.04 * 1005}{2.2 * 1128}\right)^{2} \\
& \left.+\left( \pm 1 \times \frac{-0.04 * 1005 * 28}{2.2 *(1128 * 1128)}\right)^{2}\right]^{0.5}
\end{aligned}
$$

$$
= \pm 2.5 \%
$$

Then:

$$
E \eta=\frac{2.5}{40.8}=6.13 \%
$$

Accordingly, the resulting errors of the calculated $\eta$ of the solar air heater are about $\pm 2.5 \%$.

\section{Results and discussion}

The tested heaters were studied experimentally under Kafrelsheikh, Egypt weather $\left(31^{\circ} 05^{\prime} 54^{\prime \prime} \mathrm{N}\right.$ and $30^{\circ}$ $\left.57^{\prime} 00^{\prime \prime} \mathrm{E}\right)$. The experiments were performed to study the influence of glazed entrance and guide blades on a single-pass SAH performance at various airflow rates. The tested SAHs differ in the configurations of the entrance region (glazed entrance, glazed entrance with blades, and steel entrance). In addition, the experiments at four various flow rates of air ranging from 0.013 to $0.04 \mathrm{~kg} / \mathrm{s}$ were carried out.

\subsection{Effect of entrance modifications on the temperatures of both absorber surface and airflow}

Solar intensity $\left(I_{(t)}\right)$ influences the SAH performance through the day. Figure 4 indicates the variation of $I_{(t)}$ during the day time of the experiments of the two cases at the different values of $\dot{m}$. As expected, $I_{(t)}$ varies during the day as it increases from early hours to its peak value and, then, decreases later. The daily average value of solar radiation shows its stability due to the close range of the measured values. The stability of $I_{(t)}$ can be noticed from the affinity or semicongruent curves, especially at the late hours of the day, as obviously shown in Figure 4(b). The mean average value of solar radiation is $790.4 \mathrm{~W} / \mathrm{m}^{2}$ for all days of

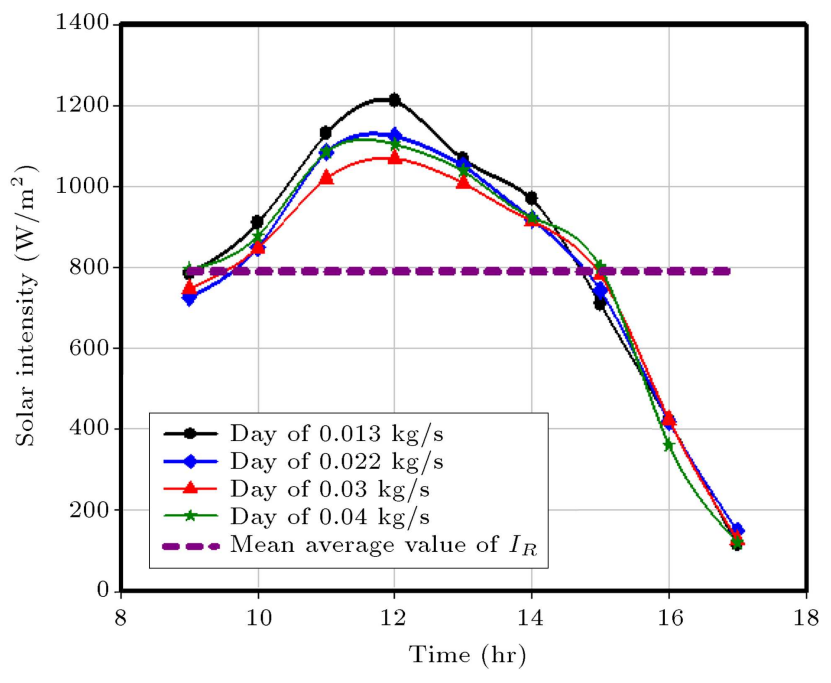

(a) Days of glazed entrance $\mathrm{SAH}$ experiments

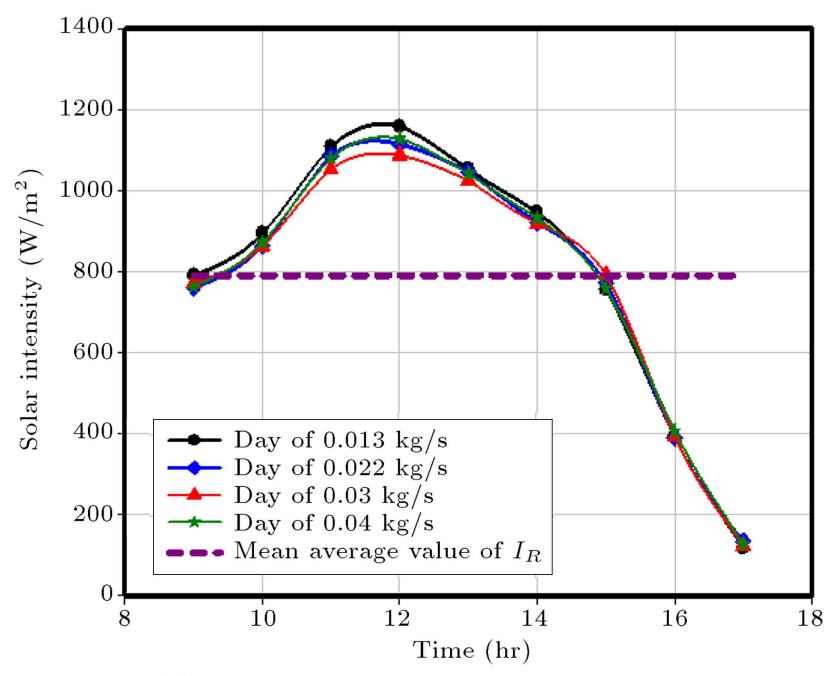

(b) Days of glazed-bladed entrance $\mathrm{SAH}$ experiments

Figure 4. The hourly variations of $I_{(t)}$ during the days of experiments.

the experiments, while the maximum recorded value is $1212 \mathrm{~W} / \mathrm{m}^{2}$.

Figure 5 shows the variations of the conventional SAH temperatures during the day time at $\dot{m}=$ $0.013 \mathrm{~kg} / \mathrm{s}$. From the results, the mean temperatures of the absorber surface during the day are 26.7, 59.6, and $65^{\circ} \mathrm{C}$ for $T_{1}, T_{2}$, and $T_{3}$, respectively, while the mean value of temperature difference of the airflow is $26.3^{\circ} \mathrm{C}$ at the same flow rate of $0.013 \mathrm{~kg} / \mathrm{s}$. Moreover, the maximum values of surface temperatures are 35 , 82 , and $88^{\circ} \mathrm{C}$ for $T_{1}, T_{2}$, and $T_{3}$, respectively, while the maximum value of temperature difference $(\Delta T)$, $T_{\text {out }}-T_{\text {in }}$, is $42^{\circ} \mathrm{C}$.

Figure 6 shows the variation of the glazed entrance $\mathrm{SAH}$ temperatures versus the experiment time at the same value of $\dot{m}=0.013 \mathrm{~kg} / \mathrm{s}$. It is noticed that the mean temperatures on the absorber surface during the day are $45.4,64.6$, and $71.1^{\circ} \mathrm{C}$ for $T_{1}, T_{2}$, 


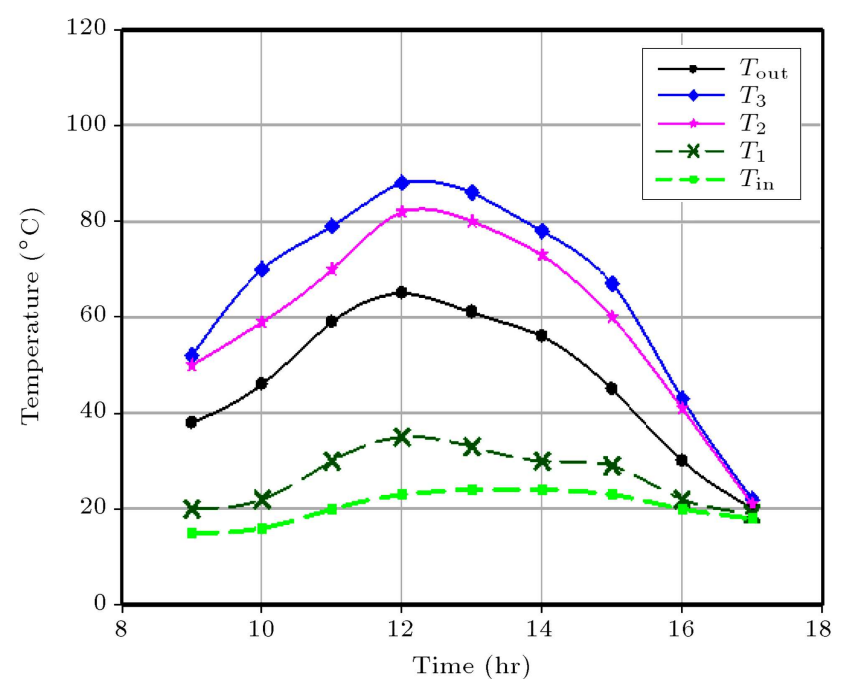

Figure 5. The hourly variations of the conventional SAH temperatures at $0.013 \mathrm{~kg} / \mathrm{s}$.

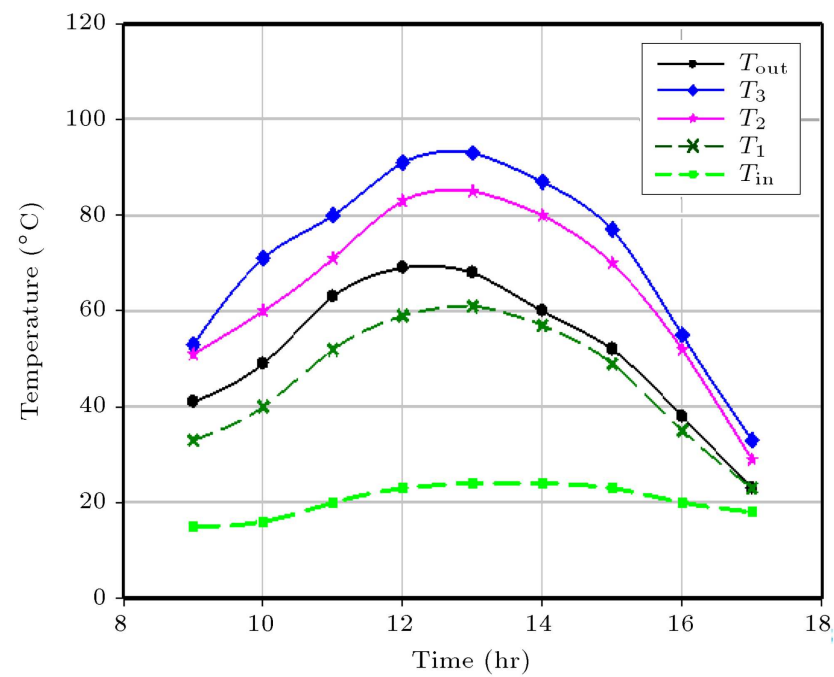

Figure 6. The hourly variations of the glazed entrance SAH temperatures at $0.013 \mathrm{~kg} / \mathrm{s}$.

and $T_{3}$, respectively. The mean value of $\Delta T$ is $31.1^{\circ} \mathrm{C}$. In addition, the maximum values of temperatures are 61,85 , and $93^{\circ} \mathrm{C}$ for $T_{1}, T_{2}$, and $T_{3}$, respectively. The maximum value of $\Delta T$ is $46^{\circ} \mathrm{C}$.

On the other side, for glazed-bladed entrance SAH, Figure 7 illustrates the variation of its temperatures versus time at the same value of $\dot{m}=0.013 \mathrm{~kg} / \mathrm{s}$. The mean temperatures of the surface during that day are $44.8,63.8$, and $70.33^{\circ} \mathrm{C}$ for $T_{1}, T_{2}$, and $T_{3}$, respectively. The mean value of $\Delta T$ is $33.1^{\circ} \mathrm{C}$. In addition, the maximum values of temperatures are 60,84 , and $92^{\circ} \mathrm{C}$ for $T_{1}, T_{2}$, and $T_{3}$, respectively. The maximum value of $\Delta T$ is $47^{\circ} \mathrm{C}$. The results show that the mean temperatures on the absorber surface of the glazed-bladed entrance SAH during the day are approximately the same for the glazed entrance $\mathrm{SAH}$ as the blades gain low value of heat from the entrance

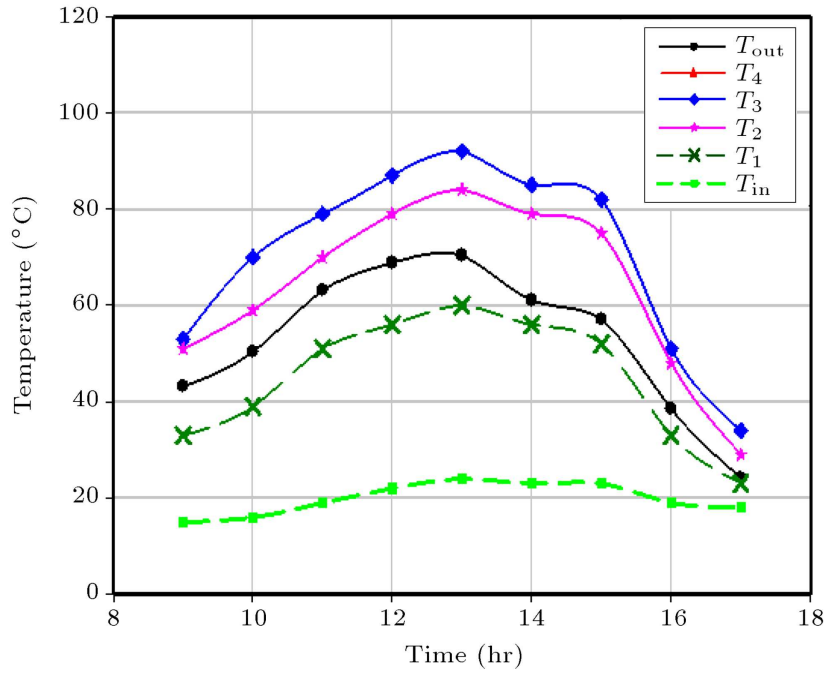

Figure 7. The hourly variations of the glazed-bladed entrance $\mathrm{SAH}$ temperatures at $0.013 \mathrm{~kg} / \mathrm{s}$.

besides the close-range of the solar radiation during the days of the experiments.

Based on the comparison of the results, both surface temperatures and $T_{\text {out }}$ of the modified SAHs are higher than their values at the conventional SAH. This may be due to the prevention of radiation from reaching the entrance due to the steel entrance. Therefore, the entrance temperature decreases. Hence, the absorber loses heat to the entrance, resulting in the decrease of the absorber temperature. Moreover, using glass cover at the entrance of the modified SAHs increases the area's exposure to the solar radiation, thus increasing the surface temperature and, hence, $T_{\text {out }}$. In addition, it is noticed that $T_{\text {out }}$ in the case of the glazed-bladed entrance $\mathrm{SAH}$ is higher than that in the glazed entrance $\mathrm{SAH}$ without blades. This may result from the good air distribution through the heater surface, which in turn enhances the heat transfer process. Hence, using entrance without blades allows for low air distribution and low heat transfer area for the same value of $\dot{m}$ and, hence, low value of $T_{\text {out }}$.

\subsection{The temperature difference of the airflow}

The temperature difference $(\Delta T)$ is one of the parameters that must be considered during describing or stating the performance of SAHs. The modifications made in the entrance region led to good improvement in $\Delta T$ for each value of $\dot{m}$. For example, at $0.022 \mathrm{~kg} / \mathrm{s}$, glazing the entrance led to enhancement of $\Delta T$ by 2 to $8^{\circ} \mathrm{C}$ over the conventional $\mathrm{SAH}$, as shown in Figure $8(\mathrm{a})$. On the other hand, the glazed-bladed entrance $\mathrm{SAH}$ outperforms the conventional one by 4 to $9^{\circ} \mathrm{C}$, as shown in Figure $8(\mathrm{~b})$.

Figure 9 shows the daily temperature difference $\left(\Delta T_{d}\right)$ versus the airflow rate for each case study. The results show that $\Delta T_{d}$ decreases as $\dot{m}$ increases. At a constant value of $\dot{m}$, the results show that the 


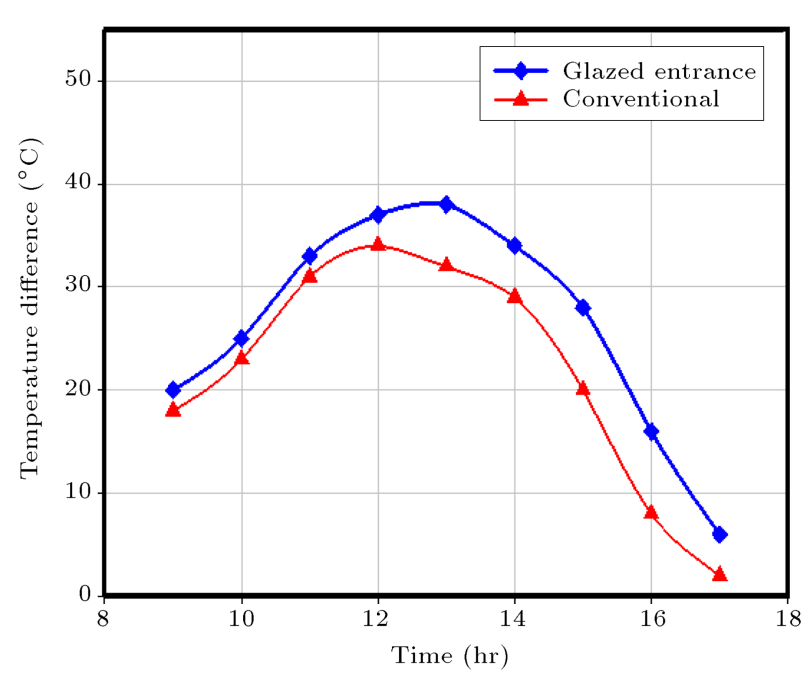

(a) Glazed entrance vs. conventional

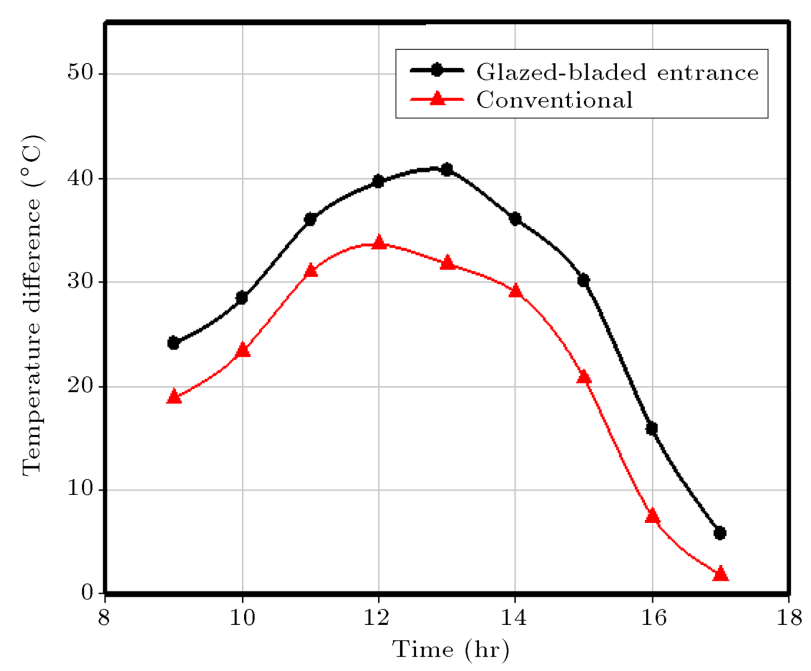

(b) Glazed and bladed entrance vs. conventional

Figure 8. Variations of the temperature difference at $0.022 \mathrm{~kg} / \mathrm{s}$.

modifications made to the entrance led to reasonable enhancement as the glazed-bladed entrance SAH leads both the glazed entrance and conventional SAHs. In addition, the glazed entrance $\mathrm{SAH}$ has higher values than the conventional one at each value of $\dot{m}$. The achieved enhancements may be due to the increase of the area's exposure to solar radiation by glazing the entrance as it becomes $2.2 \mathrm{~m}^{2}$ instead of $2 \mathrm{~m}^{2}$ in the case of conventional SAH besides eliminating the heat lost from the absorber to the entrance. Moreover, using guide blades allows good air distribution in both the entrance section and the absorber plate and reduces the dead zones in the heater. The good distribution of air enhances the heat transfer process as mentioned before. In addition, the guide blades act as fins, thus enhancing the heat transfer at entrance of heater.

According to Figure $9(\mathrm{a})$, maximum values of $\Delta T_{d}$ are 33.07 and $25.9^{\circ} \mathrm{C}$ for the glazed-bladed entrance

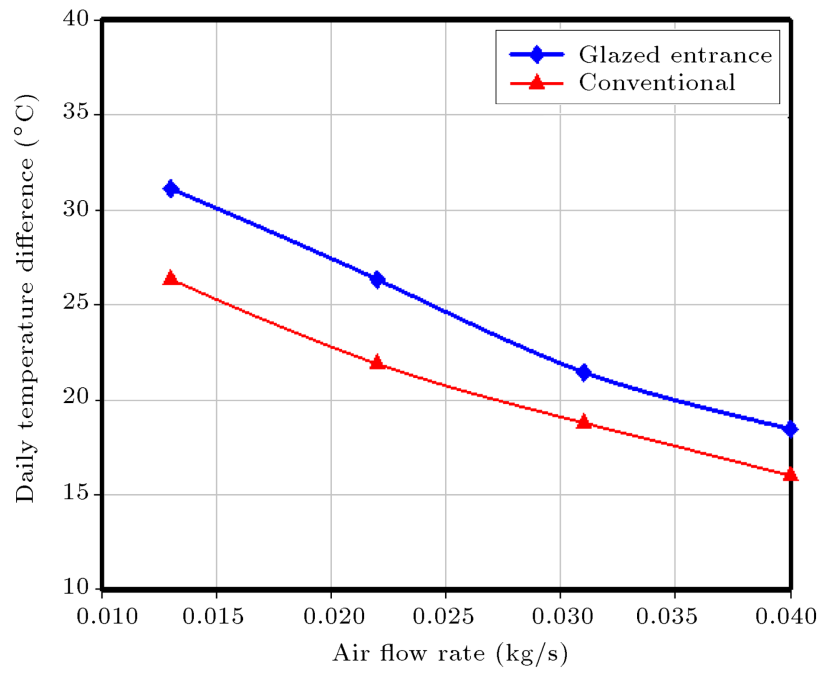

(a) Glazed entrance vs. conventional

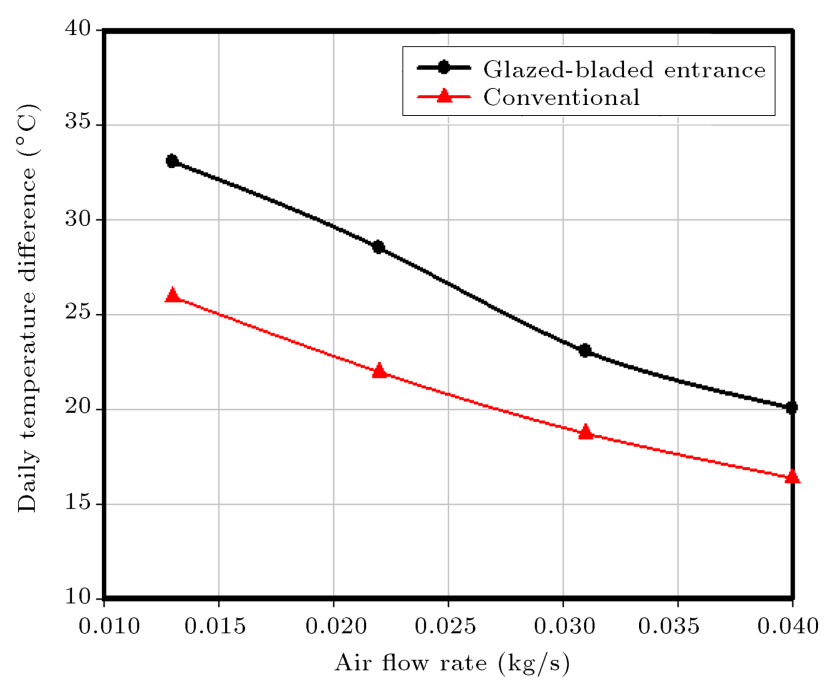

(b) Glazed and bladed entrance vs. conventional

Figure 9. Daily temperature difference versus air flow rate.

$\mathrm{SAH}$ and conventional SAH, respectively, at $\dot{m}=$ $0.013 \mathrm{~kg} / \mathrm{s}$. In addition, according to Figure 9(b), the maximum values of $\Delta T_{d}$ are 31.11 and $26.3^{\circ} \mathrm{C}$ for the glazed entrance $\mathrm{SAH}$ and conventional $\mathrm{SAH}$, respectively, at $\dot{m}=0.013 \mathrm{~kg} / \mathrm{s}$.

\subsection{The heater efficiency}

The efficiency $(\eta)$ of SAHs is the most important parameter to show their performance. For all values of $\dot{m}$, each case of the modified SAH has values of $\eta$ higher than the conventional one. In addition, the glazedbladed entrance is more efficient than the conventional one. That can be noticed from Figure 10 which indicates the thermal efficiency at an airflow rate of $0.022 \mathrm{~kg} / \mathrm{s}$, e.g., for both the modified and conventional SAHs. According to the figure, it is noticed that $\eta$ of the conventional SAH obviously decreases at the late hours of the day as opposed to the increasing 


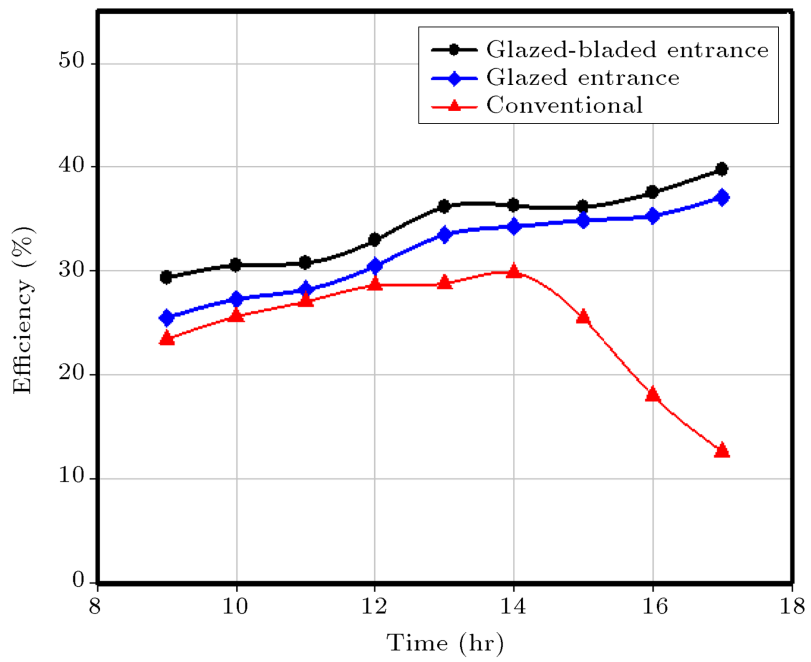

Figure 10. The thermal efficiency of tested heaters at $0.022 \mathrm{~kg} / \mathrm{s}$.

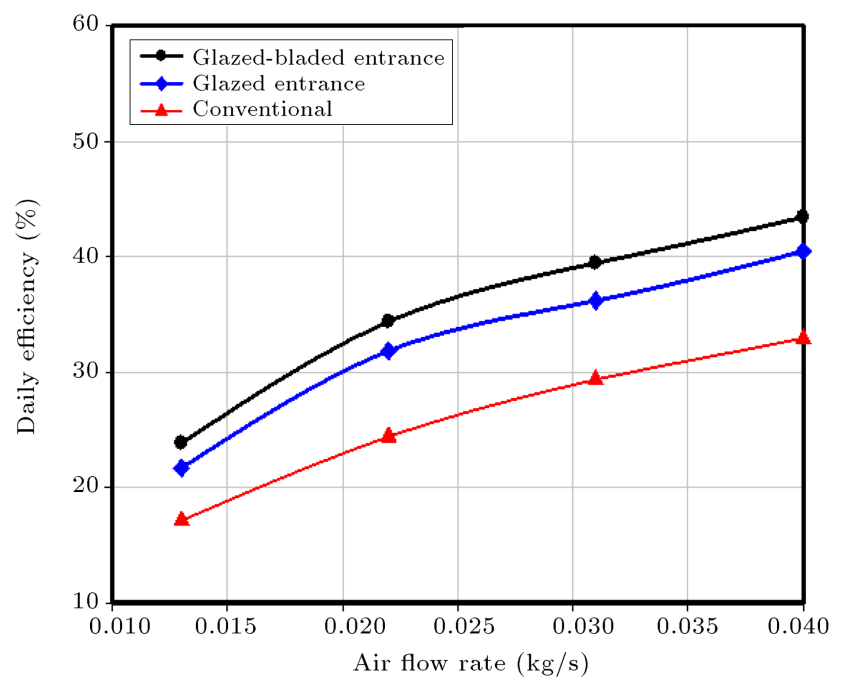

Figure 11. Daily thermal efficiency versus air flow rate.

occurrence of the modified SAHs. According to Eq. (5), the aforementioned notice is taken into account because the decrease of $\Delta T$ occurs at a small rate during the $I_{R(t)}$ reduction in the case of the modified SAHs as compared to its rate in the case of conventional $\mathrm{SAH}$. The slow decreasing rate of $\Delta T$ in the case of modified SAHs results from the modifications made to the entrance, which increased the area's exposure to solar radiation and eliminated dead zones of the air through the SAH. Moreover, at $0.022 \mathrm{~kg} / \mathrm{s}$, the glazedbladed entrance SAH overcomes the conventional SAH by 3.71 to $27.12 \%$, while the glazed entrance $\mathrm{SAH}$ is higher than the conventional SAH by 1.87 to $24.47 \%$.

Figure 11 illustrates the effect of air mass flow rate on the daily thermal efficiency $\left(\eta_{d}\right)$ for the tested SAHs. The values of $\eta_{d}$ vary in proportion to $\dot{m}$ due to the improvement in the heat transfer characteristics. In addition, the modifications made to the entrance
Table 4. Cost of fabricated SAHs.

\begin{tabular}{lc}
\hline \multicolumn{1}{c}{ Unit } & Cost $\mathbf{( \$ )}$ \\
\hline Metal sheet & 25 \\
Glass cover & 8 \\
Blower & 15 \\
Thermal insulation & 4 \\
Connection pipes and valves & 8 \\
Paint and silicon & 5 \\
Blades & 1 \\
\hline
\end{tabular}

showed good improvement in the thermal efficiency due to the prevention of the mentioned problems of steel entrance and distribution of the air by the blades. In addition, the figure clearly shows that the glazedbladed entrance SAH is more efficient than the glazed entrance and the conventional SAHs over the entire range of $\dot{m}$. The values of $\eta_{d}$ improve as $\dot{m}$ increases. According to the figure, the maximum values of $\eta_{d}$ include $43.43,40.48$, and $32.92 \%$ for the glazed-bladed entrance, glazed entrance, and conventional SAHs, respectively, at $\dot{m}$ of $0.04 \mathrm{~kg} / \mathrm{s}$. As a result, the glazedbladed SAH showed good enhancement in $\eta_{d}$ by 6.72 to $10.5 \%$ over the conventional SAH and by 2.16 to $3.25 \%$ over the glazed SAH.

\section{Cost estimation for the gained heat}

To estimate the average cost of the gained heat, the total cost $(C)$ of the assumed number of life time years $\left(n_{y}\right)$, fixed cost $(F)$, and variable cost $(V)$ is calculated as follows: $C=F+V$. The value of the variable cost $(V)$ can be assumed to be $(V=0.15 F)$ per year without the price of $\mathrm{PV}$-system. The cost of $\mathrm{PV}$-system is $\$ 300$. The fixed cost of the components of the fabricated SAHs is illustrated in Table 4 . If $n_{y}=25$ year and the number of days is 350 day/year, the following cost estimation can be calculated:

For the glazed-bladed entrance $\mathrm{SAH}$ at $\dot{m}=$ $0.04 \mathrm{~kg} / \mathrm{s}, F=\$ 366$ and $C=366+(0.15 \times 66 \times 25)=$ $\$ 613.5$. Then, $C_{\text {year }}$ is $\$ 24.54$. For average heat production of the glazed-bladed SAH of $2378 \mathrm{~kW} /$ year, the cost of one $\mathrm{kW}$ is $\$ 0.01032$.

Similarly, considering the corresponding values of fixed cost, the costs of one $\mathrm{kW}$ are $\$ 0.01099$ and $\$ 0.01351$ for glazed entrance and conventional SAHs, respectively.

\section{Conclusion}

The present experimental study aims to enhance the performance of flat-plate $\mathrm{SAH}$ by modifying the entrance region. The entrance region was covered with glass instead of steel cover. In addition, guide blades were placed in the entrance region to ensure well air 
distribution on the absorber surface. The experiments were performed at four various airflow rates between $0.013 \mathrm{~kg} / \mathrm{s}$ and $0.04 \mathrm{~kg} / \mathrm{s}$. The performance of the modified SAHs was compared with that of a conventional SAH. The results showed good improvement in both the efficiency and air temperature difference. The maximum values of the daily efficiency are $43.43,40.48$, and $32.92 \%$ for the glazed-bladed entrance SAH, glazed entrance $\mathrm{SAH}$, and conventional $\mathrm{SAH}$, respectively, at an airflow rate of $0.04 \mathrm{~kg} / \mathrm{s}$. The glazed-bladed $\mathrm{SAH}$ showed good improvement in the thermal efficiency by $6.72 \%$ to $10.51 \%$ over the conventional heater and by $2.16 \%$ to $3.25 \%$ over the glazed SAH.

\section{Nomenclature}

$\begin{array}{ll}A_{h} & \text { Surface area of SAH }\left(\mathrm{m}^{2}\right) \\ A_{p} & \text { PV pipe cross-sectional area }\left(\mathrm{m}^{2}\right) \\ C & \text { Total cost }(\$) \\ C_{p} & \text { Air specific heat }(\mathrm{J} / \mathrm{kg} \mathrm{K}) \\ F & \text { Fixed cost }(\$) \\ I_{(t)} & \text { Solar radiation intensity }\left(\mathrm{W} / \mathrm{m}^{2}\right) \\ \dot{m} & \text { Air mass flow rate }(\mathrm{kg} / \mathrm{s}) \\ N & \text { Number of variables } \\ n_{y} & \text { Number of years } \\ \mathrm{PV} & \text { Photovoltaic } \\ \mathrm{PCM} & \text { Phase Change Material } \\ Q_{u} & \text { Useful heat gained }(\mathrm{W}) \\ \mathrm{SAH} & \text { Solar Air Heater } \\ T_{\text {in }} & \text { Inlet air temperature }\left({ }^{\circ} \mathrm{C}\right) \\ T_{\text {out }} & \text { Outlet air temperature }\left({ }^{\circ} \mathrm{C}\right) \\ T_{1}, T_{2}, T_{3} & \text { Temperatures at different positions on } \\ \Delta T & \text { the absorber }\left({ }^{\circ} \mathrm{C}\right) \\ \Delta T_{d} & \text { Temperature difference of airflow }\left({ }^{\circ} \mathrm{C}\right) \\ V & \text { Daily temperature difference of airflow } \\ V_{\text {air }} & \left.\text { ( }{ }^{\circ} \mathrm{C}\right) \\ \eta_{d} & \text { Variable cost }(\$) \\ \rho & \text { Air velocity }(\mathrm{m} / \mathrm{s}) \\ & \text { Dhermal efficiency } \\ & \text { Density of air }\left(\mathrm{kg} / \mathrm{m}^{3}\right) \\ & \end{array}$

\section{References}

1. Kabeel, A.E., Hamed, M.H., Omara, Z.M., and Kandeal, A.W. "Solar air heaters: Design configurations, improvement methods and applications - A detailed review", Renew. Sustain. Energy Rev., 70, pp. 11891206 (2017).
2. Sharma, N., Bhat, I.K., and Grover, D. "Optimization of a smooth flat plate solar air heater using stochastic iterative perturbation technique", Sol. Energy, 85(9), pp. 2331-2337 (2011).

3. Baritto, M. and Bracamonte, J. "A dimensionless model for the outlet temperature of a nonisothermal flat plate solar collector for air heating", Sol. Energy, 86(1), pp. 647-653 (2012).

4. Bracamonte, J. and Baritto, M. "Optimal aspect ratios for non-isothermal flat plate solar collectors for air heating", Sol. Energy, 97, pp. 605-613 (2013).

5. Abdullah, A.S., El-samadony, Y.A.F., and Omara, Z.M. "Performance evaluation of plastic solar air heater with different cross sectional configuration", Appl. Therm. Eng., 121, pp. 218-223 (2017).

6. Chabane, F., Moummi, N., and Benramache, S. "Experimental study of heat transfer and thermal performance with longitudinal fins of solar air heater", J. Adv. Res., 5(2), pp. 183-192 (2014).

7. Alta, D., Bilgili, E., Ertekin, C., and Yaldiz, O. "Experimental investigation of three different solar air heaters: Energy and exergy analyses", Appl. Energy, 87(10), pp. 2953-2973 (2010).

8. Omojaro, A.P. and Aldabbagh, L.B.Y. "Experimental performance of single and double pass solar air heater with fins and steel wire mesh as absorber", Appl. Energy, 87(12), pp. 3759-3765 (2010).

9. Rai, S., Chand, P., and Sharma, S.P. "An analytical investigations on thermal and thermohydraulic performance of offset finned absorber solar air heater", Sol. Energy, 153, pp. 25-40 (2017).

10. Naphon, P. "On the performance and entropy generation of the double-pass solar air heater with longitudinal fins", Renew. Energy, 30(9), pp. 1345-1357 (2005).

11. Ho, C.D., Yeh, H.M., Cheng, T.W., Chen, T.C., and Wang, R.C. "The influences of recycle on performance of baffled double-pass flat-plate solar air heaters with internal fins attached", Appl. Energy, 86(9), pp. 14701478 (2009).

12. Yeh, H.M. "Upward-type flat-plate solar air heaters attached with fins and operated by an internal recycling for improved performance", J. Taiwan Inst. Chem. Eng., 43(2), pp. 235-240 (2012).

13. Ho, C.D., Chang, H., Wang, R.C., and Lin, C.S. "Performance improvement of a double-pass solar air heater with fins and baffles under recycling operation", Appl. Energy, 100, pp. 155-163 (2012).

14. Priyam, A. and Chand, P. "Thermal and thermohydraulic performance of wavy finned absorber solar air heater", Sol. Energy, 130, pp. 250-259 (2016).

15. Gao, W., Lin, W., Liu, T., and Xia, C. "Analytical and experimental studies on the thermal performance of cross-corrugated and flat-plate solar air heaters", Appl. Energy, 84(4), pp. 425-441 (2007).

16. Karim, M.A. and Hawlader, M.N.A. "Performance investigation of flat plate, v-corrugated and finned air collectors", Energy, 31(4), pp. 452-470 (2006). 
17. El-Sebaii, A.A., Aboul-Enein, S., Ramadan, M.R.I., Shalaby, S.M., and Moharram, B.M. "Thermal performance investigation of double pass-finned plate solar air heater", Appl. Energy, 88(5), pp. 1727-1739 (2011).

18. Gawande, V.B., Dhoble, A.S., Zodpe, D.B., and Chamoli, S. "Experimental and CFD investigation of convection heat transfer in solar air heater with reverse L-shaped ribs", Sol. Energy, 131, pp. 275-295 (2016).

19. Hans, V.S., Saini, R.P., and Saini, J.S. "Heat transfer and friction factor correlations for a solar air heater duct roughened artificially with multiple v-ribs", Sol. Energy, 84(6), pp. 898-911 (2010).

20. Sharma, S.K. and Kalamkar, V.R. "Experimental and numerical investigation of forced convective heat transfer in solar air heater with thin ribs", Sol. Energy, 147, pp. 277-291 (2017).

21. Boulemtafes-boukadoum, A., Benzaoui, A., and Nedjari, H.D. "Comparative study of the effects of two types of ribs on thermal performance of solar air heaters", Sci. Iran., 24, pp. 2418-2428 (2017).

22. Handoyo, E.A. and Ichsani, D. "Numerical studies on the effect of delta-shaped obstacles' spacing on the heat transfer and pressure drop in v-corrugated channel of solar air heater", Sol. Energy, 131, pp. 47-60 (2016).

23. Kulkarni, K., Afzal, A., and Kim, K. "Multi-objective optimization of solar air heater with obstacles on absorber plate", Sol. Energy, 114, pp. 364-377 (2015).

24. Yadav, S. and Kaushal, M. "Exergetic performance evaluation of solar air heater having arc shape oriented protrusions as roughness element", Sol. Energy, 105, pp. 181-189 (2014).

25. Pandey, N.K. and Bajpai, V.K. "Experimental investigation of heat transfer augmentation using multiple arcs with gap on absorber plate of solar air heater", Sol. Energy, 134, pp. 314-326 (2016).

26. Behura, A.K., Prasad, B.N., and Prasad, L. "Heat transfer, friction factor, and thermal performance of three sides artificially roughened solar air heaters", Sol. Energy, 130, pp. 46-59 (2016).

27. Prasad, B.N., Behura, A.K., and Prasad, L. "Fluid flow and heat transfer analysis for heat transfer enhancement in three sided artificially roughened solar air heater", Sol. Energy, 105, pp. 27-35 (2014).

28. Krishnananth, S.S. and Kalidasa Murugavel, K. "Experimental study on double pass solar air heater with thermal energy storage", J. King Saud Univ. - Eng. Sci., 25(2), pp. 135-140 (2012).

29. Alkilani, M.M., Sopian, K., Mat, S., and Alghoul, M.A. "Output air temperature prediction in a solar air heater integrated with phase change material", Eur. J. Sci. Res., 27(3), pp. 3334-41 (2009).

30. Moradi, R., Kianifar, A., and Wongwises, S. "Optimization of a solar air heater with phase change materials: Experimental and numerical study", Exp. Therm. Fluid Sci., (2017). doi: http://dx.doi.org/10.1016/ j.expthermflusci .2017.07.011
31. Kabeel, A.E., Khalil, A., Shalaby, S.M., and Zayed, M.E. "Improvement of thermal performance of the finned plate solar air heater by using latent heat thermal storage", Appl. Therm. Eng., 123, pp. 546553 (2017).

32. Kabeel, A.E., Khalil, A., Shalaby, S.M., and Zayed, M.E. "Experimental investigation of thermal performance of flat and v-corrugated plate solar air heaters with and without PCM as thermal energy storage", Energy Convers. Manag., 113, pp. 264-272 (2016).

33. El-Sebaii, A.A. and Al-Snani, H. "Effect of selective coating on thermal performance of flat plate solar air heaters", Energy, 35(4), pp. 1820-1828 (2010).

34. Aboul-Enein, S., El-Sebaii, A.A., Ramadan, M.R.I., and El-Gohary, H.G. "Parametric study of a solar air heater with and without thermal storage for solar drying applications", Renew. Energy, 21(3-4), pp. 505$522(2000)$.

35. Ramani, B.M., Gupta, A., and Kumar, R. "Performance of a double pass solar air collector", Sol. Energy, 84(11), pp. 1929-1937 (2010).

36. Dissa, A.O., Ouoba, S., Bathiebo, D., and Koulidiati, J. "A study of a solar air collector with a mixed 'porous' and 'non-porous' composite absorber", Sol. Energy, 129, pp. 156-174 (2016).

37. Chouksey, V.K. and Sharma, S.P. "Investigations on thermal performance characteristics of wire screen packed bed solar air heater", Sol. Energy, 132, pp. 591-605 (2016).

38. Prasad, S.B., Saini, J.S., and Singh, K.M. "Investigation of heat transfer and friction characteristics of packed bed solar air heater using wire mesh as packing material", Sol. Energy, 83(5), pp. 773-783 (2009).

39. Zheng, W., Zhang, H., You, S., Fu, Y., and Zheng, X. "Thermal performance analysis of a metal corrugated packing solar air collector in cold regions", Appl. Energy, 203, pp. 938-947 (2017).

40. Bayrak, F., Oztop, H.F., and Hepbasli, A. "Energy and exergy analyses of porous baffles inserted solar air heaters for building applications", Energy Build., 57, pp. 338-345 (2013).

41. Karsli, S. "Performance analysis of new-design solar air collectors for drying applications", Renew Energy, 32(10), pp. 1645-1660 (2007).

42. Holman, J.P., Experimental Method for Engineers, 8th Edn., p. 64, McGraw-Hill (2012).

43. Srithar, K. and Mani, A. "Studies on solar flat plate collector evaporation systems for tannery effluent (soak liquor)", Journal of Zhejiang University-Science A, 7(11), pp. 1870-1877 (2006).

\section{Biographies}

Abd Elnaby Kabeel, Professor, received his BSc and MSc degree in Mechanical Power Engineering, 
Mechanical Engineering Department, Mansoura University, Mansoura, Egypt in 1984 and 1990, respectively. He received his $\mathrm{PhD}$ degree in Mechanical Power Engineering, University of Technology, Bratislava, Slovak Republic, 1997. He is currently a Professor at the Department of Mechanical Engineering since 2008 and the Vice Dean for Postgraduate Studies and Research, Faculty of Engineering, TU, Tanta since 2016, Faculty of Engineering, TU. He was the Head of Mechanical Power Engineering Department, Faculty of Engineering, TU from 2009 till 2010 and from 2013 till 2016 and the Vice Dean for Community Service and Environmental Development, Faculty of Engineering, TU from 2010 till 2013. He was the Head of the Hydraulic and Irrigation Department from 2012 till 2013. He is an active member of Community Service and Environmental Development Committees. He is a member of the Standing Committee for Academic Upgrade Professors and Assistant Professors Edition of 2012-2015. He participated in setting a five-year research plan at Tanta University.

Prof. Kabeel has several research interests including renewable energy systems, desiccant dehumidification systems, refrigeration and air conditioning, water desalination, and environmental service projects. He has about 218 international conferences and journal papers in his record. He has several awards and honors such as Tanta University recognition award prize in Engineering Sciences in 2001, the State Award for Excellence in Engineering Sciences, Egypt in 2013, Abdul Hameed Shoman's Award for Arab Researchers, Jordan in 2014, Tanta University Award for Excellence in Performance in 2014, Tanta University Award Appreciation in 2017. Tanta University Award is the highest record of international publishing researchers among the university researchers in 2013, 2014, 2016, and 2017. He supervised about 50 Master and PhD theses, 30 of which are closed and 20 are still under preparation. He is a reviewer for several reputable journals. He is a member of the Scientific Committee in several conferences.

Mofreh H. Hamed was born in Kallin, Egypt in 1958. He received the BSc degrees in Mechanical Power Engineering in 1981, the MSc in 1986 from the University of Monufiya, Egypt, and PhD degree in Mechanical Engineering from the Moscow Power Institute (MPI) Moscow in 1994. In 1981, he joined the Department of Mechanical Power Engineering, University of Menoufiya, as a Demonstrator; in 1986, he became an Assistant Lecturer. He was an Assistant Professor, became an Associate Professor in 2001, and a Professor in 2006. He worked as a Professor at the Department of Mechanical Engineering since 2006 and the Head of Mechanical Engineering Department, Faculty of Engineering, Kafrelsheikh University from 2007 until 2010 and the Vice Dean for students' affairs and education, Faculty of Engineering, Kafrelsheikh University until 2014. Since 2014, he has worked as the Dean of Higher Institute of Engineering and Technology, HIEAT. His current research interests include desalination of water and new and renewable energy, two-phase flow, and applications of thermofluids and published several research papers in international scientific journals and conferences. In 2008, he became a member of Egyptian Universities Promotion Committees (EUPC), which lasted till now. He Awarded the University Prize for Scientific Publication every year.

Zakaria Mohamed Omara was born in Kafrelsheikh, Egypt in 1973. He received the BSc degree in Mechanical Power Engineering in 1996 and the MSc in 2003 from the University of Tanta, Egypt and $\mathrm{PhD}$ degree in Mechanical Power Engineering from University of Tanta in 2008. He joined the Department of Mechanical Power Engineering, University of Tanta, as a Demonstrator; in 2003, he became an Assistant Lecturer. He was an Assistant Professor and, then, became an Associate Professor in 2013. His current research interests include desalination of water and new and renewable energy, and published several research papers in international scientific journals and conferences.

Abdallah Wagih Kandeal was born in Kafrelsheikh, Egypt in 1990. He obtained his BSc degree in Mechanical Engineering from Kafrelsheikh University, Egypt in 2012 and his MSc degree from Tanta University, Egypt in 2018. In 2014, he joined Mechanical Engineering Department, Kafrelsheikh University, as a Demonstrator. His research interests include renewable energy. 